\title{
Argon out of thin air
}

\author{
Markku Räsänen remembers making a neutral compound featuring argon, and ponders on the reactivity \\ of this inert element.
}

$\mathrm{T}$ he discovery of the noble gases shows how innovative researchers have been when it came to separating and identifying minor amounts of components from mixtures using relatively simple tools.

First indications of an inert component in air appeared in 1785 through

Henry Cavendish's experimental studies, when he found about $1 \%$ of an unreactive component. He could not, however, identify the unreactive species, which turned out to be argon, and the names connected with its discovery are Lord Rayleigh and Sir William Ramsay (pictured). In 1892, Rayleigh and Ramsay's exceptionally skilful eudiometric measurements, after chemical separation of the constituents, revealed that the density of nitrogen prepared by removing oxygen, carbon dioxide and water from air with heated copper differed from the density of nitrogen prepared from ammonia.

The understanding that this meant another element, $\mathrm{X}$, was present, and its identification through spectroscopy - not available at the time of Cavendish's studies - came two years later. Ramsay suggested ${ }^{1}$ to Lord Rayleigh: "Seeing that X is very inactive, what do you think of argon $\alpha \rho \gamma o v$ (idle) for a name?" They had been working separately but on very similar studies, and made a joint announcement. Their findings on noble gases were recognized in 1904 by the Nobel Prize in Physics for Rayleigh and that in Chemistry for Ramsay.

Argon didn't fit in the periodic table known at the time, and it was Ramsay who suggested including an additional column, group 18. Helium, and other elements subsequently discovered, were to find their place with the 'rare gases'. This name is somewhat misleading, however, with argon being the third most abundant atmospheric substance after nitrogen and oxygen (it makes up about $0.94 \%$ of our atmosphere). A preferred term for group 18 is 'noble gases', in reference to their reluctance to bond

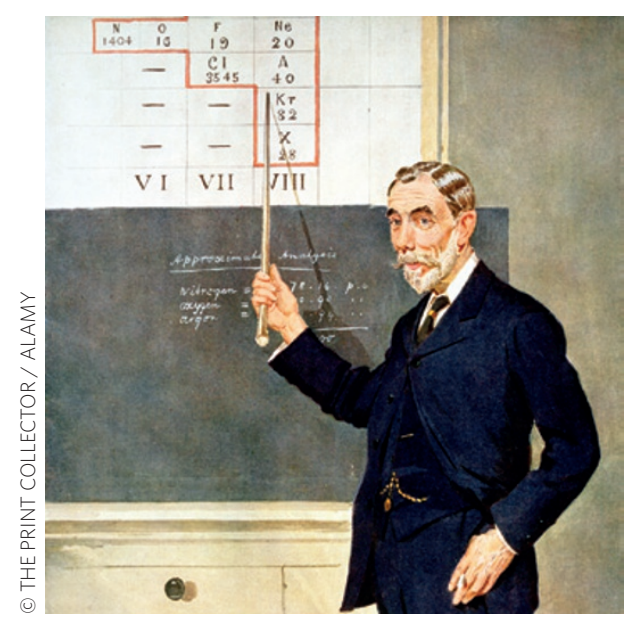

chemically. This idleness of argon finds many chemical and industrial uses, for example as a chemically inert atmosphere, in welding, food storage and insulating windows. Argon isotopes also serve in geological age determinations, and laser technology uses argon extensively, in the form of $\mathrm{Ar}^{+}$cations in gas lasers and excited ArF in exciplex lasers.

Owing to the same inertness, it has been hard to coerce argon into forming neutral compounds. In 1995, noble gas $(\mathrm{Ng})$ hydrides were discovered that have a general structure of $\mathrm{HNgY}$, where $\mathrm{Ng}$ is $\mathrm{Kr}$ or Xe and $\mathrm{Y}$ an electronegative atom or fragment. These molecules consist mainly of a covalent bond between $\mathrm{H}$ and $\mathrm{Ng}$ and an ionic bond between $\mathrm{Ng}$ and $\mathrm{Y}$.

Perhaps surprisingly, as early as 1995, lowlevel quantum chemical calculations suggested the existence of a chemical compound containing an $\mathrm{Ar}_{\text {atom }}^{2}$ : hydridoargon fluoride, HArF, that was predicted to be preparable at cryogenic conditions. The synthesis of HArF from $\mathrm{H}, \mathrm{Ar}$ and $\mathrm{F}$ in solid argon was tried, in a similar manner to that of $\mathrm{HXeI}$ from $\mathrm{H}+\mathrm{Xe}+\mathrm{I}$, but several attempts in my group failed. Still, during the following several years, more and more extensive computational studies strengthened the belief that HArF can exist. After learning the reasons for the failed experiments, mainly due to improper handling of the reactive precursor HF, the first signals of this new species were obtained in my group on 21 December 1999 - a time of the year conducive to experimentation, with no interfering students present in the lab. Conclusive experimental results were obtained from the vibrational spectral effects of $\mathrm{H} / \mathrm{D}$ and ${ }^{36} \mathrm{Ar} /{ }^{40} \mathrm{Ar}$ isotopic substitutions ${ }^{3}$. A neutral molecule containing argon - I couldn't have wished for a better Christmas present.

A number of stable argon compounds have been computationally predicted, and are waiting for experimental verification. Recent extensions of this chemistry include, for example, the preparation and characterization of ArBeS (ref. 4) and ArAuF (ref. 5). Our chemical understanding of the group 18 elements is changing, as progress in noble gas chemistry has slowly started to enter schoolbooks, starting with xenon, which shows extensive bond formation.

The future will tell as to what extent noble gas hydrides and related species exist. At present, the number of experimentally characterized noble gas hydrides amounts to about 30 , and it is easy to design more of such metastable molecules. Chemists want to explore the frontiers of chemistry for basic knowledge, and research of novel bonds between noble gases and other elements offers a challenging field for this. The excellent computational tools constantly being developed with experimental work offers very good possibilities for success.

MARKKU RÄSÄNEN is in the Department of Chemistry, University of Helsinki, PO Box 55 (A. I.Virtasen aukio 1), FIN-00014 University of Helsinki, Finland.

e-mail: markku.rasanen@helsinki.fi

\section{References}

1. Klein, M. L. \& Venables, J. A. (eds) Rare Gas Solids Vol. 1, p19 (Academic Press, 1976).

2. Pettersson, M., Lundell, J. \& Räsänen, M. J. Chem. Phys. 102, 6423-6431 (1995).

3. Khriachtchev, L., Pettersson, M., Runeberg, N., Lundell, J. \& Räsänen, M. Nature 406, 874-876 (2000).

4. Wang, Q. \& Wang, X. J. Phys. Chem. A 117, 1508-1513 (2013).

5. Wang, X., Andrews, L., Brosi, F. \& Riedel, S. Chem. Eur. J. 19, 1397-1409 (2013).
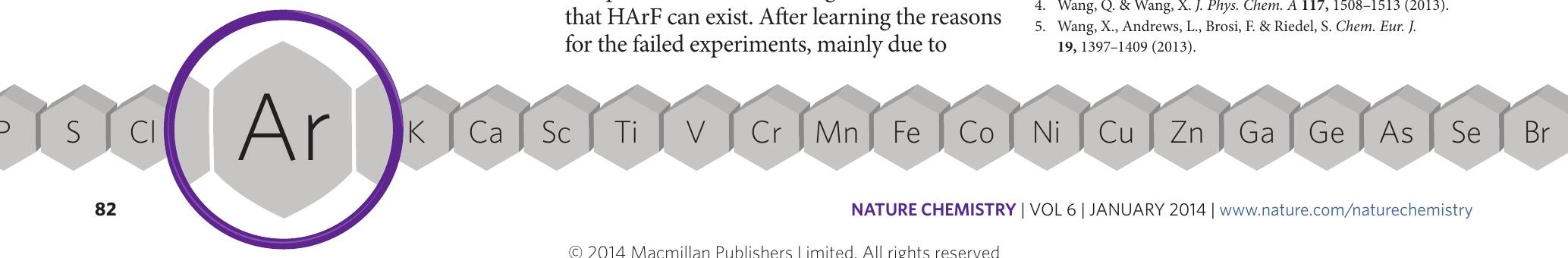